\title{
Hour Times Micromole per Liter per Milligram per Kilogram
}

National Cancer Institute

\section{Source}

National Cancer Institute. Hour Times Micromole per Liter per Milligram per Kilogram.

NCI Thesaurus. Code C132446.

Hours times micromoles per liter, divided by milligrams per kilograms. 